\title{
The chemical and biochemical oxygen demand reduction by Armillaria tabescens in malathion supplemented culture medium
}

\author{
Yildirim N. ${ }^{1}$, Erguven G.O. ${ }^{1 *}$ and Adar E. ${ }^{2}$ \\ ${ }^{1}$ Munzur University, Faculty of Engineering, Department of Environmental Engineering, 62100, Tunceli, Turkey \\ ${ }^{2}$ Yildiz Technical University, Faculty of Civil Engineering, Department of Environmental Engineering, 34220, Istanbul, Turkey \\ Received: 01/03/2018, Accepted: 26/09/2018, Available online: 27/09/2018 \\ *to whom all correspondence should be addressed: e-mail: gokhanondererguven@gmail.com \\ https://doi.org/10.30955/gnj.002660
}

\begin{abstract}
The extensive use of pesticides for controlling insects has been widely used in agricultural activities. However, the indiscriminate use of the pesticides has inflicted serious harmful problems to humans in the ecosystem. Our study aims to evaluating the capacity of Armillaria tabescens to remove the chemical oxygen demand (COD) and biochemical oxygen demand $\left(\mathrm{BOD}_{5}\right)$ at different concentration of malathion insecticide $(50,100$ and $150 \mathrm{ppm})$ under agitated (130 rpm) submerged culture conditions at $27^{\circ} \mathrm{C}$ after 8 and 15 days. According to our results, $A$. tabescens has achieved COD reduction as 52.39, 27.24 , and $38.30 \%$ at concentration of 50, 100 and $150 \mathrm{ppm}$ respectively on 15 days. The $\mathrm{BOD}_{5}$ reduction rates were found as $78.2,74.76$ and $81.26 \%$ at 50,100 and $150 \mathrm{ppm}$ concentration respectively at the end of the $15^{\text {th }}$ days. At the end of this time period, the dried biomass of $A$. tabescens was weighted and we have suggested that malathion in medium reduced the biomass production compared the control group (Sabouraud dextrose broth $+A$. tabescens). Our experiments have focused that; $A$. tabescens could be an alternative and useful fungus for bioremediation of wastewater containing malathion insecticide.
\end{abstract}

Keywords: A. tabescens, malathion, chemical oxygen demand, biochemical oxygen demand.

\section{Introduction}

During the last half decade, pesticides have been the major concern of the agricultural activities. To be helpful for increasing the quality and efficiency of production, pesticides industry became obvious. (Oliveira-Silva, 2001).

Today, organophosphorus insecticides are the largest classes of pesticides and they are identified with their high degradation rates. The biodegradation of the malathion is more feebleness due to its eco-friendly, low investment and also low application costs (Khan et al., 2016). In the environment, pesticides are permanent organic compounds and they withstand to chemical and biological degradation (Buccini, 2003).
One of the organophosphate insecticides is malathion and this insecticide can use for control of field crops from insects, pests, animal parasites and flies. The liquid form of malathion insecticide can be degraded biologically (Barlas, 1996).

The process that for remove the pesticides from the receiving environment consists of some technologies correlated with conventional treatment methods and these methods are not enough for eliminate the contaminants clearly (Ikehata and El-Din, 2006).

In the last decades, ecofriendly methods like using different microorganisms have preferred for remediate contaminated receiving environments. With this advance, bioremediation methods are generally preferred compared to other physicochemical methods (Kidd et al., 2009). Biodegradation is a basic factor for eliminating the adverse effects of organophosphorus pesticides in the environment. Many scientists have focused on the microbial strains have an increasing degradation efficiency of the organophosphorus pesticides (Sorensen et al., 2008). Researches about biodegradation are useful for eliminate the toxic effects of these insecticides by microorganisms. Various receiving environments polluted from pesticides includes microorganisms that capable of biodegrade them (Brajesh KS, Walker, 2006)

Armillaria root rot, which can be caused by several members of the basidiomycete genus Armillaria, occurs worldwide on a wide variety of hardwood and softwood plants $A$. tabescens belonging to white-rot fungi is a non-toxic, edible fungus (Hood et al.,1991).

In this study, we focused on evaluate the removal performance of $A$. tabescens on suggested concentrations of malathion insecticide $(50,100$ and $150 \mathrm{ppm})$ for local farmers in their agricultural activities. We also try to determine the removal efficiency of this fungus on malathion insecticide with most important environment parameters such as COD and $\mathrm{BOD}_{5}$. 


\section{Materials and methods}

\subsection{Chemicals}

Sabouraud dextrose agar (SDA) and sabouraud dextrose broth (SDB) were obtained from Lab M Limited

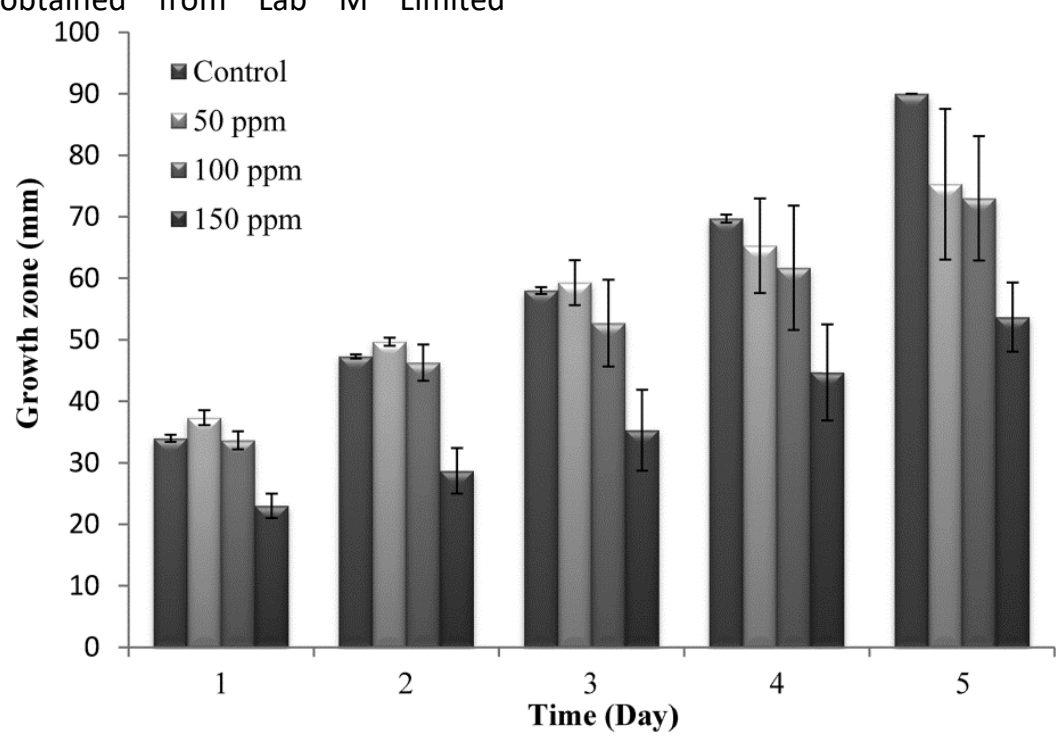

Figure 1. Agar plate screening of growth in SDA media supplemented with malathion ( 5 days)

\subsection{Fungus}

The fungal strains of $A$. tabescens are in the current station in our stock culture collections. The strains were sustained on SDA slants at $4^{\circ} \mathrm{C}$ in refrigerator.

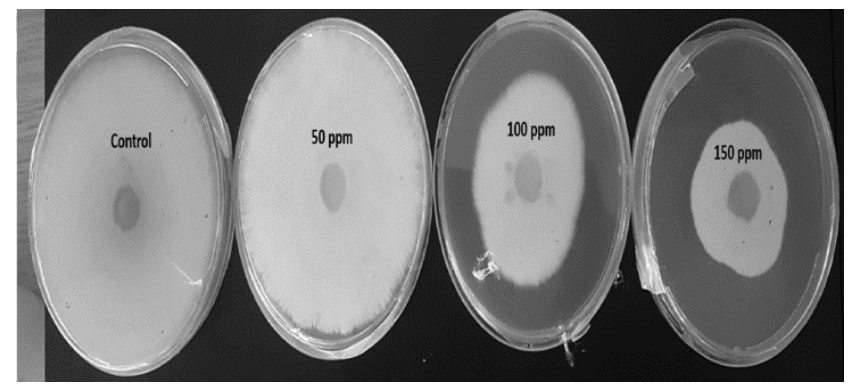

Figure 2. Growth of fungus in different concantration of malathion after 5 day

\subsection{Monitoring the growing rate of $A$. tabescens in SDA media}

For SDA plate monitoring the growing rate of A. tabescens, mycelial plugs (5 $\mathrm{mm}$ diameter) were placed into the center of Petri dishes (90 mm diameter) containing 50, 100 and $150 \mathrm{ppm}$ of malathion insecticide. The plates were incubated at $27 \stackrel{\circ}{\circ}$ in the dark until they were exactly colonized with the fungus or after maximum period of 7 days. The diameters $(\mathrm{mm})$ of the growing zones were defined in two diagonal directions of the agar plate. Plates containing the fungal mycelial plug but not supplemented with malathion used as blank media. All experiments were performed in triplicate.
(United Kingdom) with a lot number of 143118. Malathion insecticide was purchased from sigma-aldrich (Germany) with a CAS number of 121-75-5.

\subsection{Agitated culture conditions preparation}

Submerged culture medium and inoculum of $A$. tabescens were cultured at $27^{\circ} \mathrm{C}$ on SDA slants in glass tube. After incubation period of seven days, conidial suspensions were prepared and these were used for the preparation of inoculum. $10 \mathrm{ml}$ of the suspension solutions were transferred into a $250 \mathrm{ml}$ flask containing SDB and agitated on a rotary shaker at $130 \mathrm{rpm}$ for periods of 10 days at $27^{\circ} \mathrm{C}$. At the end of the incubation, flasks homogenized and then these homogenized mycelial cultures were used as inoculum for studies under submerged culture medium. $10 \mathrm{ml}$ homogenized mycelial culture was transferred into $250 \mathrm{ml}$ flasks containing $150 \mathrm{ml} \mathrm{SDB}, \mathrm{SDB}+50, \mathrm{SDB}+100$, and $\mathrm{SDB}+150 \mathrm{ppm}$ of malathion insecticide on an agitated incubator for 8 and 15 days at $27{ }^{\circ} \mathrm{C}$ in triplicate. After incubation, all flasks filtered for removing fungal biomass and then filtrate was used in COD and BOD5 reduction experimental studies.

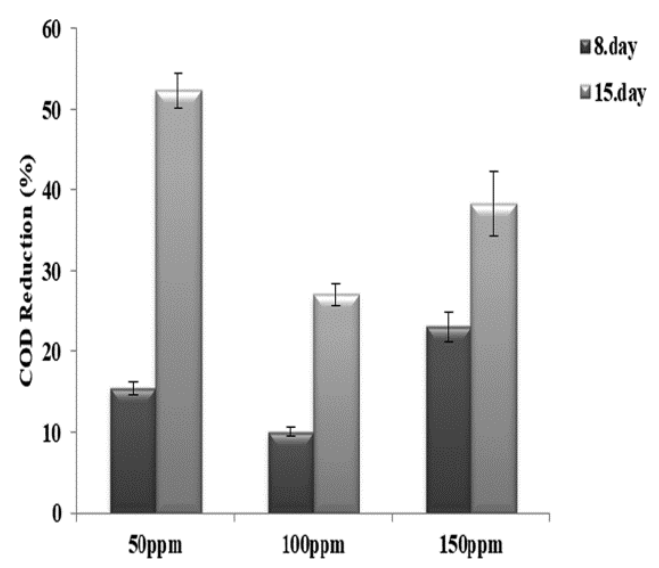

Figure 3. COD reduction in submerged culture medium supplemented with malathion 


\section{5. $C O D$ and $B O D_{5}$ reduction experiments}

Closed reflux titrimetric method were used for the COD experiments according to the Standard Method $5220 \mathrm{C}$ while $\mathrm{BOD}_{5}$ test was performed by the line of Standard Method 5210B (5 day BOD 5 ) test (APHA, 1998). All experiments were performed triplicate.

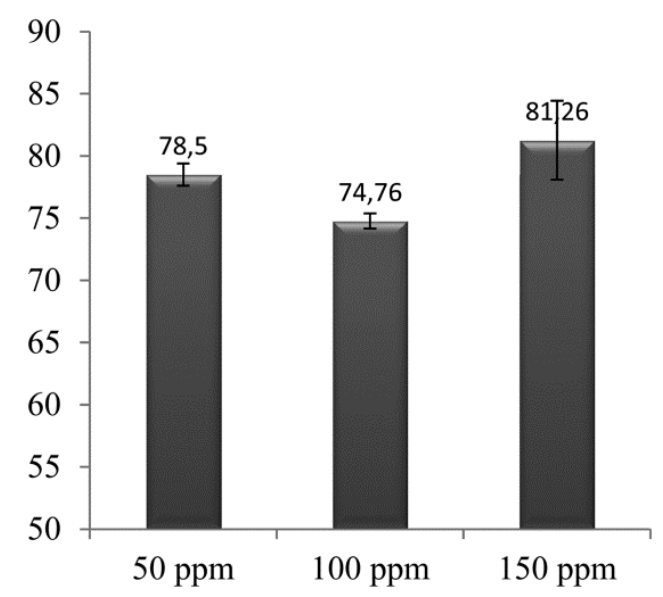

Figure 4. BOD reduction in Submerged Culture Medium supplemented with malathion

\subsection{Dry biomass assays}

Dry matter of $A$. tabescens, was determined by drying fungal biomass, taken from the filtration of flasks at end of the 15 days in $105^{\circ} \mathrm{C}$ for 48 hours to a constant weight.

\subsection{Statistical analyses}

All statistical analyses were performed with SPSS (SPSS Inc., Chicago, IL, USA). The data presented are the averages of the results of three replicates with a standard error (SE). To compare the dry biomass, growth zone, COD and $\mathrm{BOD}_{5}$ reduction in media, the data were analyzed by analysis of variance (ANOVA).

\section{Results and discussion}

\subsection{Screening of growth zone in solid media}

All growth zones of $A$. tabescens in agar media were demonstrated in Figure 1 . In the SDA medium, the diameter of the $A$. tabescens colony decreased with the increase in the malathion residuals in the medium. A. tabescens showed a reduction of over $40 \%$ in the colony growth diameter in the lowest concentration of malathion in comparison with the control experiment at 5 days. At higher concentrations of malathion, growing of A. tabescens decrease.

After the 5 days period, growth zones in control group and malathion supplemented groups were given in Figure 2. Malathion could to be little toxic effect to the $A$. tabescens used in this study for malathion supplemented groups, since slightly inhibited the fungal growth. Similar results were found in previous studies. The screening of fungal growth in media with malathion indicated that the A. tabescens is metabolized malathion.

\subsection{Removal of $\mathrm{COD}$ and $\mathrm{BOD}_{5}$}

Reduction rates of $\mathrm{COD}$ and $\mathrm{BOD}_{5}$ in the media supplemented with malathion have showed different results depend on the difference in concentrations and incubation period in the submerged culture medium. According to the results of COD assays; in medium with 50 ppm malathion, after 8 day, reduction was seen about $15.49 \pm 0.82 \%$ and after 15 day, reduction increased to $52.39 \pm 2.13 \%$. In $100 \mathrm{ppm}$, reduction value of $10.12 \% \pm 0.52$ increased to $27.14 \pm 1.37 \%$ and finally at $150 \mathrm{ppm}$ medium with malathion, reduction rates were increased from 8 day to 15 day from $23.12 \pm 1.88 \%$ to $38.30 \pm 4.01 \%$ respectively (Figure 3 ). According to these results, best reduction performance on COD occurred in $50 \mathrm{ppm}$ concentrations after $15^{\text {th }}$ day. For $\mathrm{BOD}_{5}$ assays, the best removal performance seen on $150 \mathrm{ppm}$ concentrations of malathion as $81.3 \%$ after 15 days (Figure 4). (Mawgoud, 2005) studied the biodegradation efficacy of $P$. putida and revealed that this bacterium has a great potential for malathion degradation. As a result, degradation rate of malathion was occurred about $72 \%$ at a concentration of $125 \mathrm{mgL}^{-1}$. Some studies about biodegradation of malathion has been investigated in Republic of Korea (Kim et al., 2005) and Egyptian soils (Mawgoud, 2005). Zhongli et al. (2001) suggested microbial growth on different concentrations of organophosphorus pesticides as sources of carbon have been previously reported. Yonten et al. (2017) studied the biodegradation capacity of $P$. eryngii var. ferulae for COD and they found $P$. eryngii var. ferulae was a suitable species for bioremediation of pesticides. In a previous research on biodegradation of chlorsulfuron, COD removal efficiencies were observed between $70 \%$ and $93 \%$ on B. simplex, B. muralis, M. luteus, M. yunnanensis and C. tetani bacterial species (Erguven and Yildirim, 2016). Erguven (2018) observed that removal rates of herbicide acetochlor in agitated culture media obtained by $T$. geodes, C. cicadae, M. owariensis, M. cylindrosporae and $V$. chlamydosporium were $90,90,74,61$, and $52 \%$ as COD and 80, 76, 76, 54 and $50 \%$ as $\mathrm{BOD}_{5}$ respectively. According on these reduction rates, it could be concluded that $T$. geodes has the highest removal rate for both parameters.

\subsection{Dry biomass}

The amount of the dry fungal biomass was measured for control, 50, 100 and 150 ppm medium as 1.17, 092, 0.86 and $0.49 \mathrm{~g}$ respectively (Figure 5). According to these results; in the submerged culture medium, $150 \mathrm{ppm}$ concentration of malathion insecticide reduced the growth of fungus clearly. Similarly, in some another studies, fungal biomass production in the agitated culture medium in the presence of some pesticides (cypermethrin + chlorpyrifos and triazamate etc.), by the observation of inhibitory zones, was inhibit as $82 \%$ with the results occurred (Slavikova and Vadkertiova, 2003). Buck and Burpee (2002) reported significant reduction of yeast phylloplane population by the other ergosterol biosynthesis inhibitor propiconazole. Erguven et al. (2017) studied about biodegradation of insecticide malathion 
with $P$. chrysosporium and they found the amount of the dry fungal biomass was measured as 1.05, 0.72, 0.52 and $1.15 \mathrm{~g}$ for 50, 100, $150 \mathrm{ppm}$ and control medium respectively. According to these results, it is revealed that especially $100 \mathrm{ppm}$ and $150 \mathrm{ppm}$ concentration of malathion clearly reduced the growth of fungus in submerged culture medium.

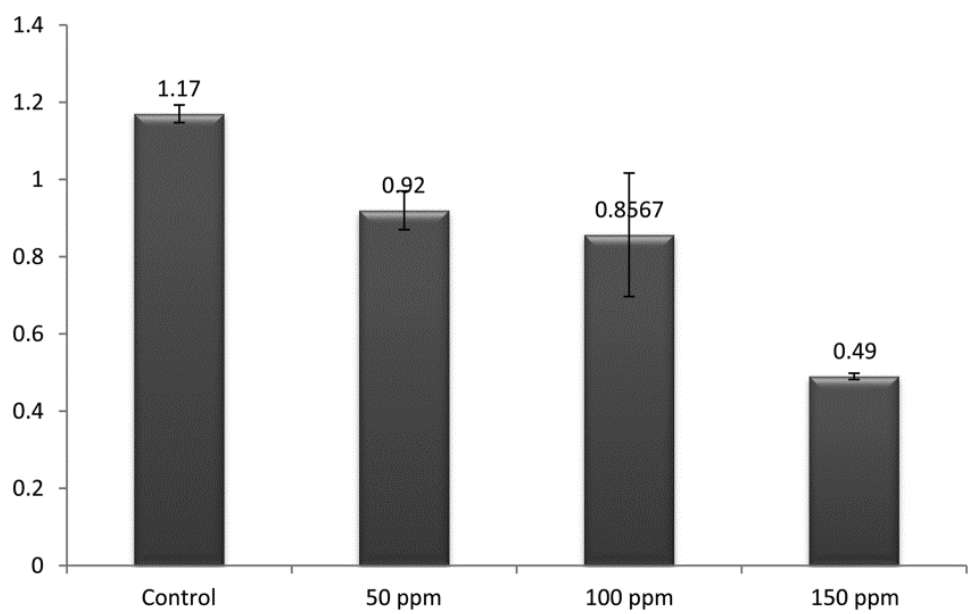

Figure 5. Dry fungal biomass in submerged culture medium supplemented with malathion after 15 days

\section{Conclusions}

According to the results of the experiments, A. tabescens might be used in malathion bioremediation with a significant $\mathrm{COD}$ and $\mathrm{BOD}_{5}$ reduction in submerged culture conditions supplemented with malathion. A. tabescens may be also used in bioremediation of some other pesticides. In addition, some studies with other insecticides and herbicides with microorganisms are needed to confirm its clear mechanism of bioremediation process with other important environmental parameters such as active material, total organic carbon, etc. The data reported in this study indicate that $A$. tabescens can survive by degrading this kind of insecticide. Most microorganisms live in agricultural soil, enable to degrade insecticides. Additionally, since using other physical and chemical methods to degrade insecticides is very difficult and also expensive, most of researchers suggested the use of these cultures for easily degradation. In recent years, several studies on bioremediation/biodegradation of pesticides from agricultural fields were conducted. In this study, we found that $A$. tabescens fungi might be used in bioremediation studies in aquatic ecosystems polluted by malathion. A. tabescens also can be use for removal pesticide pollution from agricultural fields and receiving environments. $\mathrm{COD}$ and $\mathrm{BOD}_{5}$ parameters can give us valuable information for understanding the biodegradation efficiency.

\section{References}

Abdel Mawgoud Y. (2005), Molecular characterization of malathion biode-grading enzymes extracted from Egyptian bacterial isolates. New Egyptian Journal of Microbiology, 10, 226-231.
APHA (1998), Standard Methods for the Examination of Water and Wastewater, twentieth Edition, American Public Health Association, Washington, DC.

Barlas N.E. (1996), Toxicological assessment of biodegraded malathion in albino mice. The Bulletin of Environmental Contamination and Toxicology, 57, 705-712.

Brajesh K.S. and Walker A. (2006), Microbial degradation of organophosphorus compounds. FEMS Microbiology Reviews, 30, 428-471.

Buccini J. (2003), The Development of a Global Treaty on Persistent Organic Pollutants (POPS) Persistent Organic Pollutants, Springer, pp. 13-30.

Buck J.W. and Burpee L.L. (2002), The effects of fungicides on the phylloplane yeast populations of creeping bentgrass. Canadian Journal of Microbiology, 48, 522-529.

Erguven G.O. (2018). Comparison of Some Soil Fungi in Bioremediation of Herbicide Acetochlor Under Agitated Culture Media. The Bulletin of Environmental Contamination and Toxicology, 100, 570-575.

Erguven G.O. and Yildirim N. (2016). Efficiency of some soil bacteria for chemical oxygen demand reduction of synthetic chlorsulfuron solutions under agiated culture conditions. Cellular and Molecular Biology, 62, 92-96.

Erguven, G.O., Yildirim N. and Adar E. (2017). The ability of Phanerochaete chrysosporium (ME446) on chemical oxygen demand remediation in submerged culture medium supplemented with malathion insecticide. Desalination and Water Treatment, 94, 231-235.

Hood I.A., Redfern D.B. and Kile G.A. (1991), Armillaria in planted hosts. In: Shaw, III, C.G.

Ikehata K. and El-Din M.G. (2006), Aqueous pesticide degradation by hydrogen peroxide/ultraviolet irradiation and Fenton-type advanced oxidation processes: a review. Journal of Environmental Engineering and Science, 5, 81e135.

Khan S., Zaffar H., Irshad U., Ahmad R., Khan A.R., Shah M.M., Bilal M., Iqbal M. and Naqvi T. (2016), Biodegradation of 
malathion by Bacillus licheniformis strain ML-1, Archives of Biological Sciences, Belgrade, 68, 51-59.

Kidd H. and James D.R. (1991), The Agrochemical Handbook $3^{\text {rd }}$ ed. The Royal Society of Chemistry, Cambridge.

Kile, G.A. (Eds.), Armillaria Root Disease, Agric. Handbook No. 691. USDA Forest Service, Washington, DC, pp. 122-149.

Kim Y.H., Ahn J.Y., Moon S.H. and Lee J. (2005), Biodegradation and detoxification of organophosphate insecticide, malathion by Fusarium oxysporumf. sp. pisicutinase. Chemosphere, 60, 1349-1355.

Luo X., Xu X., Yu M., Yang Z. and Zheng L. (2008), Characterisation and immunostimulatory activity of an $\alpha$ $(1 \rightarrow 6)$-d-glucan from the cultured Armillariella tabescens mycelia. Food Chemistry, 111, 357-363.

Oliveira-Silva J.J., Alves S.R., Meyer A., et al. (2001), Influence of socioeconomic factors on the pesticides poisoning, Brazil. Revista de Saúde Pública April, 35, 130-135.

Perucci P., Dumontet S., Bufo S.A., Mazzatura A. and Casucci C. (2000), Effects of organic amendment and bentgrass. Canadian Journal of Microbiology 48, 522-529.

Slavikova E. and Vadkertiova R. (2003), Effects of Pesticides on Yeasts Isolated from Agricultural Soil, Zeitschrift fur Naturforschung., 58c, 855-859.

Sorensen S.R., Albers C.N. and Aamand J. (2008), Rapid mineralization of the phenylurea herbicide diuron by Variovorax sp. strain SRS16 in pure culture and within a twomember consortium. Applied and Environmental Microbiology, 74, 2332-2340.

Yonten V., Alp H., Yildirim N., Yildirim N.C. and Ogedey A. (2017). Investigation of optimum conditions for efficient $C O D$ reduction in synthetic sulfamethazine solutions by Pleurotus eryngii var. ferulae using response surface methodology. Journal of the Taiwan Institute of Chemical Engineers, 80, 349-355.

Zhongli C., Shunpeng L. and Guoping F. (2001), Isolation of methyl parathion-degrading strain M6 and cloning of the methyl parathion hydrolase gene. Applied and Environmental Microbiology, 67, 4922-4925. 